\title{
Estimated enterolignans, lignan-rich foods, and fibre in relation to survival after postmenopausal breast cancer
}

\author{
K Buck', AK Zaineddin', A Vrieling', J Heinz², J Linseisen ${ }^{3}$, D Flesch-Janys ${ }^{2,4}$ and J Chang-Claude*, I \\ 'Unit of Genetic Epidemiology, Division of Cancer Epidemiology, German Cancer Research Center (DKFZ), Im Neuenheimer Feld 58I, Heidelberg, \\ Germany; ${ }^{2}$ Department of Cancer Epidemiology/Clinical Cancer Registry, University Cancer Center Hamburg (UCCH), Martinistrasse 52, \\ 20246 Hamburg, Germany; ${ }^{3}$ Institute of Epidemiology, Helmholtz Center Munich, Ingolstädter Landstrasse I, 86746 Neuherberg, Germany; \\ ${ }^{4}$ Department of Medical Biometry and Epidemiology, Center for Experimental Medicine, University Medical Center Hamburg-Eppendorf, \\ Martinistrasse 52, 20246 Hamburg, Germany
}

BACKGROUND: Lignans - oestrogenic substances present in various foods - are associated with postmenopausal breast cancer risk, but not much is known regarding their effects on survival.

METHODS: In a follow-up study of 2653 postmenopausal breast cancer patients diagnosed between 200I and 2005, vital status and causes of death were verified through end of 2009. Hazard ratios (HRs) and 95\% confidence intervals (Cls) for estimated enterolignans, lignan-rich foods, and dietary fibre in relation to overall survival (OS) and breast cancer-specific survival (BCSS) were assessed using Cox proportional hazards models stratified by age at diagnosis and adjusted for prognostic/confounding factors. RESULTS: Median follow-up time was 6.4 years, and 321 women died, 235 with breast cancer. High estimated enterolactone and enterodiol levels were associated with significantly lower overall mortality (highest quintile, $\mathrm{HR}=0.60,95 \% \mathrm{Cl}=0.40-0.89$, $P_{\text {Trend }}=0.02$ and $\mathrm{HR}=0.63,95 \% \mathrm{Cl}=0.42-0.95, P_{\text {Trend }}=0.02$, respectively). Fibre intake was also associated with a significantly lower overall mortality. Differentiated by median fibre intake, associations with estimated enterolignans were still evident at low but not high fibre intake. There was no effect modification by oestrogen receptor status and menopausal hormone therapy. CONCLUSION: Postmenopausal breast cancer patients with high estimated enterolignans may have a better survival. British Journal of Cancer (201 I) 105, I I5I-II57. doi:I0.1038/bjc.201 I.374 www.bjcancer.com Published online 13 September 2011 (c) 20II Cancer Research UK

Keywords: phyto-oestrogens; enterolactone; seeds; fibre; postmenopausal breast cancer prognosis; survival

Lignans are biphenolic compounds in plant foods with a structure similar to oestrogens. They are the major source of phytooestrogens in Western populations and are primarily present in fibre-rich foods (such as seeds, grains, vegetables, and fruits) (Adlercreutz, 2007; Sonestedt and Wirfält, 2010). In the human gut, plant lignans are converted by intestinal bacteria to the enterolignans, enterolactone and enterodiol, which are bioactive and are subsequently absorbed (Adlercreutz, 2007).

There are several mechanisms by which enterolignans may protect against cancer. They were shown to have weak oestrogenic activity and may bind to oestrogen receptors (ERs) (Mueller et al, 2004; Penttinen et al, 2007). Moreover, they may exert effects via oestrogen receptor-independent mechanisms, such as inhibition of tumour growth and angiogenesis, as well as stimulation of apoptosis and of sex hormone-binding globulin production (SHBG) (Adlercreutz et al, 1987; Power et al, 2006; Adlercreutz, 2007; Mense et al, 2008; Saarinen et al, 2008, 2010).

Lignans have been associated with postmenopausal breast cancer risk; however, the results were inconsistent. Two recent meta-analyses found lignans to be associated with a small risk reduction only in postmenopausal but not in premenopausal

*Correspondence: Dr J Chang-Claude; E-mail: j.chang-claude@dkfz.de Received 31 March 2011; revised 19 August 2011; accepted 22 August 20 I ; published online 13 September 201 I women based on studies in Eastern and Western countries (Velentzis et al, 2009; Buck et al, 2010).

There is limited epidemiological evidence on the potential effects of lignans with respect to breast cancer prognosis. Two studies, conducted in the United States, assessed the association of dietary plant lignans with survival in postmenopausal breast cancer patients (Fink et al, 2007; McCann et al, 2009). One study reported that a higher dietary lignan intake was associated with a better prognosis (McCann et al, 2009), whereas the other found no association (Fink et al, 2007). Neither study examined the association of estimated enterolignans with survival.

Dietary fibre and a diet rich in fibre has been (inconsistently) associated with a better survival after breast cancer (Holmes et al, 1999; Kroenke et al, 2005; Kellen et al, 2009). As lignans originate partly from fibre complex in foods, it is still unclear whether associations observed with fibre-rich foods are attributed to fibre or enterolignans or both.

Thus, we investigated the association of estimated amounts of enterolignans (enterolactone and enterodiol), dietary intake of lignan-rich foods (seeds, bread, vegetables, and fruit), and dietary fibre intake with overall and breast cancer-specific survival (BCSS) in a large German cohort of postmenopausal breast cancer patients. Furthermore, we examined whether this association is modified by hormone receptor status of the tumours and menopausal hormone therapy use at diagnosis. 


\section{MATERIALS AND METHODS}

\section{Study population}

Our study population comprised breast cancer patients aged $50-74$ years who participated in a population-based case-control study carried out in two German study regions (Hamburg and Rhein-Neckar-Karlsruhe (RNK)) (Flesch-Janys et al, 2008) and were followed up until the end of 2009. The patients were diagnosed with a histologically confirmed primary invasive or in situ breast tumour between 1 January 2001 and 30 September 2005 in Hamburg and between 1 August 2002 and 31 July 2005 in the RNK region and were identified through participating clinics and the Cancer Registry of Hamburg. Postmenopausal status was defined by one or more of the following criteria: last menstrual bleeding at least 12 months before diagnosis, bilateral oophorectomy, or $>55$ years with unclear menopausal status due to hysterectomy or hormone use. We included 2668 postmenopausal patients who completed a food frequency questionnaire (FFQ) and did not have missing information on cancer before the breast cancer diagnosis and were not previously diagnosed with cancer (except for in situ carcinoma, and basal and squamous cell skin carcinoma).

At recruitment, in-person interviews were performed to collect information on demographic, anthropometric, socioeconomic, and lifestyle factors. Moreover, information on suggested and established breast cancer risk factors and possible prognostic factors was obtained. Clinical and pathological records were used to collect information on further prognostic factors.

The study was approved by the ethics committees of the University of Heidelberg, the University of Hamburg, and the Medical Board of the State of Rheinland-Pfalz, and conducted in agreement with the Helsinki declaration. All participants provided written informed consent at recruitment as well as during follow-up.

\section{Dietary data}

At recruitment, a self-administered validated 176 -items FFQ was completed by the patients, which recorded the nutritional habits one year before diagnosis. This FFQ was similar to the one used in the European Prospective into Cancer and Nutrition (EPIC) study, and nutrient intake (e.g., dietary fibre) was calculated using the German food composition table Bundeslebensmittelschluessel II.3 (Bundesinstitut für Gesundheitlichen Verbraucherschutz und Veterinärmedizin) (Bohlscheid-Thomas et al, 1997a,b). For each food item, the information about portion size and consumption frequency was used to calculate intakes in grams per day $\left(\mathrm{g} \mathrm{day}^{-1}\right)$. The two enterolignans, enterolactone and enterodiol, were estimated from data on incubation with human faeces, in which the bioavailable enterolignans were calculated per $100 \mathrm{~g}$ of ingested foods (Thompson et al, 1991; Linseisen et al, 2004).

Two lignan-rich food items, sunflower-/pumpkinseeds and sesame/flaxseeds, were added to the original EPIC-FFQ for this specific study. Mean daily intake in $\mathrm{g} \mathrm{day}^{-1}$ was estimated for each food item.

A top and bottom energy cutoff of $0.5 \%$ was used, as the data were considered unreliable in extreme ranges of energy intake (energy range: $425-4577 \mathrm{kcal} \mathrm{day}^{-1}$ ), resulting in 2653 patients finally included in the statistical analyses.

\section{Outcome definition}

Vital status of all patients was ascertained via local population registries through the end of 2009, and causes of death were verified by death certificates and coded based on ICD-10 classifications. The end points of interest were overall survival (OS) and BCSS. The OS included death from any cause whereas for
BCSS, deaths from breast cancer (coded as ICD-10 C50) were events of interest and deaths from other causes were censored at date of occurrence. Women without an event of interest were censored either at date of last information or end of 2009. Median follow-up time was calculated as time between diagnosis and the event of interest or censoring using the reverse Kaplan-Meier estimation (Schemper and Smith, 1996).

\section{Statistical analysis}

Differences in baseline characteristics between deceased and non-deceased patients were tested using the $\chi^{2}$-statistic. The Kruskal-Wallis test was used to evaluate differences in the levels of enterolignans and lignan-rich foods between deceased and nondeceased patients. Spearman's correlation coefficients were used to correlate enterolignan intake with other dietary intake variables.

Cox proportional hazards models were used to estimate hazard ratios (HRs) for OS and BCSS, and their 95\% confidence intervals (CIs) associated with enterolignans and fibre (in quintiles) using the lowest quintile as reference group. For the assessment of seed intake and prognosis, non-consumers were used as the reference category, and were compared with low consumers (intake below median consumption of the consumers) and high consumers (intake above and equal to median consumption of the consumers). Total bread (white, brown, and whole-grain), vegetable, and fruit intake were categorised into tertiles using the lowest tertile as reference group.

All analyses were stratified by age at diagnosis (in 1-year categories) and adjusted for the established prognostic factors tumour size $(<2 \mathrm{~cm}, 2-5 \mathrm{~cm}, \geqslant 5 \mathrm{~cm}$, growth into chest wall, neoadjuvant chemotherapy-treated carcinoma, in situ carcinoma), nodal status $(0,1-3,4-9, \geqslant 10$, neoadjuvant chemotherapytreated carcinoma, in situ carcinoma), metastasis (yes, no, in situ carcinoma), grade $(1+2,3+4$, in situ carcinoma, neo-adjuvant chemotherapy-treated carcinoma), and ER/progesterone receptor (PR) status (in situ carcinoma, $\mathrm{ER}+/ \mathrm{PR}+, \mathrm{ER}+/ \mathrm{PR}-$ or $\mathrm{ER}-/ \mathrm{PR}+, \mathrm{ER}-/ \mathrm{PR}-$, neoadjuvant chemotherapy-treated carcinoma). Further covariates for the multivariable regression analyses were determined using a backward elimination procedure based on $P<0.05$ in the likelihood ratio test for the covariate or a $>10 \%$ change in HR for variable of interest. Thus, the models additionally included breast cancer detection type (physician-detected by clinical examination/mammography/ultrasound, self-detected by palpation/secretion/pain), use of menopausal hormone therapy at diagnosis (current, never/past), diabetes (yes, no), and study centre (Hamburg and RNK). Additionally, energy intake (kcal day ${ }^{-1}$, continuous) was included as a confounder in the multivariable regression models. The HER2-neu status, cardiovascular diseases, alcohol consumption, smoking habits, occupational status, type of surgery, phyto-oestrogen supplementation, adult BMI, physical activity, and further dietary variables (i.e., vitamin $\mathrm{C}$, fat, carbohydrate, protein, bread, vegetable, and fruit intake), as well as hormonal, chemo-, and radiotherapy did not affect the risk estimates in the Cox models. Potential confounding by fibre was assessed by additional adjustment of the models of enterolignans for dietary fibre intake (continuous). Similarly, the model for dietary fibre was additionally adjusted for enterolactone levels (continuous). Additionally, subgroup analyses by low and high dietary fibre intake ( $<$ median $v s \geqslant$ median) were performed. Tests for trend of the HRs were performed using continuous values of the variables.

To assess the functional form of the continuous variables in the multivariable Cox models, fractional polynomials were applied. The models with the best -2 log likelihoods were selected (Royston et al, 1999), resulting in a linear association between the log HR and exposure variables for OS and BCSS. The test of Grambsch and Therneau (Grambsch and Therneau, 1994) was used to test the 
proportional hazards assumption and was found to hold for all analyses.

Effect modification was evaluated using the Q-statistic. Sensitivity analyses were performed by median time between diagnosis of breast cancer and date of FFQ completion, and by exclusion of phyto-oestrogen (isoflavone-containing) supplement users. Moreover, a subgroup analysis was conducted for patients with earlystage breast cancer (stage I-IIIa). Possible effect modification was assessed using analyses stratified by ER status of the tumour (positive $v s$ negative), ER/PR status of the tumour (ER- or PRpositive $v s$ ER-/PR-negative), and menopausal hormone therapy use at diagnosis (current $v s$ past/never).

For all analyses, two-sided $P$-values $<0.05$ were considered significant. No adjustment for multiple testing was performed because of the exploratory character of this study. All analyses were performed using $\mathrm{R}$ version 2.9.2 ( $\mathrm{R}$ Development Core Team, Vienna, Austria) and SAS version 9.2 (SAS Institute, Cary, NC, USA).

\section{RESULTS}

\section{Baseline characteristics}

Selected baseline characteristics of postmenopausal breast cancer patients are presented in Table 1. Median age at diagnosis of the

Table I Distribution of sociodemographic variables and prognostic factors for 2653 postmenopausal breast cancer patients by vital status

\begin{tabular}{|c|c|c|c|c|c|}
\hline & \multicolumn{2}{|c|}{ Alive } & \multicolumn{2}{|c|}{ Deceased } & \multirow{2}{*}{$\begin{array}{c}\chi^{2} \\
P \text {-value }\end{array}$} \\
\hline & $\mathbf{N}$ & $\%$ & $\mathbf{N}$ & $\%$ & \\
\hline Age at diagnosis (years) & & & & & $<0.01$ \\
\hline $50-54$ & 170 & 7.3 & 22 & 6.9 & \\
\hline $55-59$ & 541 & 23.2 & 73 & 22.7 & \\
\hline $60-65$ & 760 & 32.6 & 80 & 24.9 & \\
\hline $65-70$ & 622 & 26.7 & 88 & 27.4 & \\
\hline $70-74$ & 239 & 10.3 & 58 & 18.1 & \\
\hline Adult BMl $\left(\mathrm{kg} \mathrm{m}^{-2}\right)$ & & & & & $<0.01$ \\
\hline$<18.5$ & 66 & 2.8 & 10 & 3.1 & \\
\hline $18.5-25$ & 1757 & 75.3 & 212 & 66.0 & \\
\hline $25-30$ & 438 & 18.8 & 80 & 24.9 & \\
\hline$>30$ & 71 & 3.0 & 19 & 5.9 & \\
\hline Tumour size & & & & & $<0.01$ \\
\hline$<2 \mathrm{~cm}$ & 1296 & 55.6 & 94 & 29.3 & \\
\hline $2-5 \mathrm{~cm}$ & 715 & 30.7 & $|4|$ & 43.9 & \\
\hline$\geqslant 5 \mathrm{~cm}$ & 61 & 2.6 & 22 & 6.9 & \\
\hline Growth into chest wall & 36 & 1.5 & 28 & 8.7 & \\
\hline In situ & 155 & 6.7 & 4 & 1.3 & \\
\hline Neoadjuvant chemotherapy & 64 & 2.7 & 24 & 7.5 & \\
\hline Missing & 5 & 0.2 & 8 & 2.5 & \\
\hline Nodal status & & & & & $<0.01$ \\
\hline 0 & 1507 & 64.6 & 121 & 37.7 & \\
\hline $1-3$ & 455 & 19.5 & 95 & 29.6 & \\
\hline $4-9$ & 99 & 4.3 & 31 & 9.7 & \\
\hline$\geqslant 10$ & 48 & 2.1 & 38 & 11.8 & \\
\hline In situ & 155 & 6.7 & 4 & 1.3 & \\
\hline Neoadjuvant chemotherapy & 64 & 2.7 & 24 & 7.5 & \\
\hline Missing & 4 & 0.2 & 8 & 2.5 & \\
\hline Metastasis & & & & & $<0.01$ \\
\hline No & 2145 & 92.0 & 263 & 81.9 & \\
\hline Yes & 23 & 1.0 & 48 & 15.0 & \\
\hline In situ & 155 & 6.7 & 4 & 1.3 & \\
\hline Missing & 9 & 0.4 & 6 & 1.9 & \\
\hline Grade & & & & & $<0.01$ \\
\hline $\mathrm{G} 1+\mathrm{G} 2$ & 1589 & 68.1 & 148 & 46.1 & \\
\hline $\mathrm{G} 3+\mathrm{G} 4$ & 517 & 22.2 & 143 & 44.6 & \\
\hline
\end{tabular}

Table I (Continued)

\begin{tabular}{|c|c|c|c|c|c|}
\hline & \multicolumn{2}{|c|}{ Alive } & \multicolumn{2}{|c|}{ Deceased } & \multirow{2}{*}{$\begin{array}{c}\chi^{2} \\
P \text {-value }\end{array}$} \\
\hline & $N$ & $\%$ & $N$ & $\%$ & \\
\hline In situ & 155 & 6.7 & 4 & 1.3 & \\
\hline Neoadjuvant chemotherapy & 64 & 2.7 & 24 & 7.5 & \\
\hline Missing & 7 & 0.3 & 2 & 0.6 & \\
\hline ER/PR status & & & & & $<0.01$ \\
\hline $\mathrm{ER}+/ \mathrm{PR}+$ & |39| & 59.7 & 149 & 46.4 & \\
\hline $\mathrm{ER}+/ \mathrm{PR}-$ or $\mathrm{ER}-/ \mathrm{PR}+$ & 411 & 17.6 & 59 & 18.4 & \\
\hline $\mathrm{ER}-/ \mathrm{PR}-$ & 304 & 13.0 & 84 & 26.2 & \\
\hline In situ & 155 & 6.7 & 4 & 1.3 & \\
\hline Neoadjuvant chemotherapy & 64 & 2.7 & 24 & 7.5 & \\
\hline Missing & 7 & 0.3 & 1 & 0.3 & \\
\hline HER2-neu status & & & & & $<0.01$ \\
\hline Positive & 360 & 15.4 & 72 & 22.4 & \\
\hline Negative & 1528 & 65.5 & 195 & 60.8 & \\
\hline In situ & 155 & 6.7 & 4 & 1.3 & \\
\hline Neoadjuvant chemotherapy & 64 & 2.7 & 24 & 7.5 & \\
\hline Missing & 225 & 9.7 & 26 & 8.1 & \\
\hline Breast cancer detection type & & & & $<0.01$ & \\
\hline Self-detected & 1147 & 49.2 & 241 & 75.1 & \\
\hline Physician-detected & 1175 & 50.4 & 80 & 24.9 & \\
\hline Missing & 10 & 0.4 & 0 & 0.0 & \\
\hline \multicolumn{3}{|c|}{ Menopausal hormone therapy use at diagnosis } & & $<0.01$ & \\
\hline No/past & $|15|$ & 49.4 & 226 & 70.4 & \\
\hline Yes & 1165 & 50.0 & 93 & 29.0 & \\
\hline Missing & 16 & 0.7 & 2 & 0.6 & \\
\hline Diabetes & & & & & $<0.01$ \\
\hline No & 2158 & 92.5 & 278 & 86.6 & \\
\hline Yes & $17 \mid$ & 7.3 & 42 & 13.1 & \\
\hline Missing & 3 & 0.1 & 1 & 0.3 & \\
\hline Cardiovascular disease & & & & & $<0.01$ \\
\hline No & 1197 & 51.3 & $|3|$ & 40.8 & \\
\hline Yes & 1135 & 48.7 & 190 & 59.2 & \\
\hline Surgery type & & & & & $<0.01$ \\
\hline Breast ablation & 263 & 11.3 & 76 & 23.7 & \\
\hline Breast conservation & 775 & 33.2 & 76 & 23.6 & \\
\hline Missing & 1294 & 55.5 & 169 & 52.7 & \\
\hline \multicolumn{3}{|c|}{ Leisure time physical activity (since age 50) } & & 0.38 & \\
\hline$<28$ MET h per week & 608 & 26.1 & 92 & 28.7 & \\
\hline$\geqslant 28$ MET h per week & |70| & 72.9 & 229 & 71.3 & \\
\hline Missing & 23 & 1.0 & 0 & 0.0 & \\
\hline Phyto-oestrogen supplement use & & & 0.1 & & \\
\hline No & 2313 & 99.2 & 321 & 100.0 & \\
\hline Yes & 19 & 0.8 & 0 & 0.0 & \\
\hline Smoking & & & & & 0.75 \\
\hline Never & 1276 & 54.7 & 175 & 54.5 & \\
\hline Former & 648 & 27.8 & 85 & 26.5 & \\
\hline Current & 408 & 17.5 & 61 & 19.0 & \\
\hline Alcohol (g day ${ }^{-1}$ ) & & & & & 0.53 \\
\hline 0 & 316 & 13.6 & 42 & 13.1 & \\
\hline$<19$ & 1719 & 73.7 & 231 & 72.0 & \\
\hline$\geqslant 19$ & 296 & 12.7 & 48 & 15.0 & \\
\hline Missing & I & 0.0 & 0 & 0.0 & \\
\hline
\end{tabular}

Abbreviations: $\mathrm{BMI}=$ body mass index; $\mathrm{ER}=$ oestrogen receptor; $\mathrm{HER} 2$-neu $=$ human epidermal growth factor receptor 2; $\mathrm{PR}=$ progesterone receptor; $\mathrm{MET}=$ metabolic equivalent value.

patients was 63 years (interquartile range $=9$ years). Compared with the non-deceased patients, those who died within the followup period were older, were more likely to have higher adult BMI, larger tumours, more lymph node involvement, metastases, higher grade, ER-/PR-negative tumours, diabetes, self-detected tumours, 
and HT use at diagnosis. Deceased patients also had significantly lower dietary intake of sunflower-/pumpkinseeds, fibre, vegetables, and fruit, as well as lower exposure to estimated enterolignans compared with non-deceased patients (all $P<0.05$; Table 2).

Total estimated enterolignans correlated positively with dietary sunflower-/pumpkinseed and sesame/flaxseed intake (correlation of 0.27 and 0.26 , respectively), and with fibre intake (correlation of 0.73). Patients with higher enterolignan exposure had higher energy, carbohydrates, protein, fat, potato, bread, vegetable, and fruit intake (data not shown).

\section{Prognostic association of enterolignans and lignan-rich foods}

During a median follow-up time of 6.4 years, a total of 321 deaths occurred, of which 235 were due to breast cancer. Further causes of death included other cancers $(n=41)$, cardiovascular diseases $(n=22)$, and other causes $(n=23)$.

Higher estimated levels of enterolactone, enterodiol, and dietary fibre were associated with significantly reduced overall mortality, with significantly reduced adjusted HRs for the highest compared with the lowest quintile $(\mathrm{HR}=0.60,95 \% \mathrm{CI}=0.40-0.89$, $P_{\text {Trend }}=0.02, \mathrm{HR}=0.63,95 \% \mathrm{CI}=0.42-0.95, P_{\text {Trend }}=0.02$, and $\mathrm{HR}=0.52, \quad 95 \% \quad \mathrm{CI}=0.32-0.82, \quad P_{\text {Trend }}=0.01, \quad$ respectively; Table 3). Multivariable regression modelling using fractional polynomials confirmed linear associations between exposure variables and OS. Associations of enterolignans and fibre with BCSS were similar to that with OS; however, the HRs were not statistically significant.

Additional adjustment for dietary fibre intake in the assessments of estimated enterolignans with respect to OS did not substantially alter the associations; however, they became nonsignificant (Supplementary Table 1). The association of dietary fibre with overall mortality also became nonsignificant after adjustment for enterolactone (Supplementary Table 1). When differentiated according to median dietary fibre intake, higher levels of both enterolactone and enterodiol were still significantly associated with lower overall mortality for the low fibre intake but not high fibre intake group, although the HRs for the highest quintiles were nonsignificant (highest quintile for enterolactone $\mathrm{HR}=0.32,95 \%$ $\mathrm{CI}=0.10-1.04, P_{\text {Trend }}=0.03$ and $\mathrm{HR}=1.25,95 \% \mathrm{CI}=0.44-3.58$, $P_{\text {Trend }}=0.08$, respectively, and enterodiol $\mathrm{HR}=0.48, \quad 95 \%$
$\mathrm{CI}=0.21-1.07, P_{\text {Trend }}=0.01$ and $\mathrm{HR}=1.08,95 \% \mathrm{CI}=0.38-3.04$, $P_{\text {Trend }}=0.05$, respectively; Table 4 ).

For the lignan-rich foods, there was no trend in association by level of consumption although the HRs for low $v s$ no consumption were significant for sunflower-/pumpkinseeds $(0.74, \quad 95 \%$ $\mathrm{CI}=0.55-0.99)$ and for sesame/flaxseeds $(0.73,95 \% \mathrm{CI}=0.54-$ 0.99; Table 5). There was no significant trend with increasing intake of any lignan-rich food (all $P_{\text {Trend }}>0.1$ ). No association between lignan-rich foods and BCSS was observed (Table 5).

Sensitivity analysis by median time between diagnosis and FFQ completion (168 days, interquartile range $=414$ days $)$ showed no significant heterogeneity between risk estimates for the estimated enterolignans, fibre, and lignan-rich foods and OS (all $P_{\text {heterogeneity }}>0.05$ ). Exclusion of 19 phyto-oestrogen supplement users also did not alter the risk estimates for any variable in association with OS (data not shown).

In 2228 patients with early-stage (I-IIIa) disease, the HRs for overall mortality associated with estimated enterolignans, fibre, and lignan-rich foods were similar to that in the total study population (all $P_{\text {heterogeneity }}>0.1$ ). The reductions in HR associated with the highest compared with the lowest quintiles were stronger for estimated enterolactone $(\mathrm{HR}=0.49,95 \% \mathrm{CI}=0.30$ $\left.0.80, P_{\text {Trend }}=0.02\right)$, enterodiol $(\mathrm{HR}=0.56,95 \% \mathrm{CI}=0.35-0.91$, $\left.P_{\text {Trend }}=0.02\right)$, and fibre $(\mathrm{HR}=0.45,95 \% \quad \mathrm{CI}=0.26-0.80$, $\left.P_{\text {Trend }}=0.01\right)$.

There was no significant heterogeneity in the associations with estimated enterolignans and fibre by ER status (Supplementary Table 2), ER/PR status, and menopausal hormone therapy use at diagnosis (all $P_{\text {heterogeneity }}>0.1$; data not shown).

\section{DISCUSSION}

Our data provide first evidence that postmenopausal patients with higher levels of the estimated enterolignans, enterolactone and enterodiol, may have a significantly increased OS, which is independent of ER status of the tumour. Higher dietary fibre intake was also associated with a significantly better survival after breast cancer. In addition, the lower mortality associated with higher enterolignan levels in women with lower than median fibre intake provides some evidence for an effect of enterolignans, which is independent of fibre intake.

Table 2 Consumption levels of estimated enterolignans, dietary fibre, and lignan-rich foods by vital status

\begin{tabular}{|c|c|c|c|c|c|}
\hline Item & Vital status $(N)$ & Mean & Median & IQR & P Kruskal-Wallis \\
\hline Fibre $\left(g_{\text {day }}{ }^{-1}\right)$ & $\begin{array}{l}\text { Alive (2332) } \\
\text { Deceased (32I) }\end{array}$ & $\begin{array}{l}20.8 \\
20.0\end{array}$ & $\begin{array}{l}20.0 \\
19.6\end{array}$ & $\begin{array}{l}8.1 \\
8.2\end{array}$ & 0.04 \\
\hline Sesame/flaxseeds $\left(\mathrm{g} \mathrm{day}^{-1}\right)$ & $\begin{array}{l}\text { Alive (2332) } \\
\text { Deceased (32I) }\end{array}$ & $\begin{array}{l}2.5 \\
1.7\end{array}$ & $\begin{array}{l}0.0 \\
0.0\end{array}$ & $\begin{array}{l}1.4 \\
1.4\end{array}$ & 0.05 \\
\hline Bread $\left(\right.$ g day $\left.^{-1}\right)$ & $\begin{array}{l}\text { Alive (2332) } \\
\text { Deceased (32I) }\end{array}$ & $\begin{array}{l}131.9 \\
136.4\end{array}$ & $\begin{array}{l}123.8 \\
130.7\end{array}$ & $\begin{array}{l}73.5 \\
76.5\end{array}$ & 0.29 \\
\hline
\end{tabular}

Abbreviation: $\mathrm{IQR}=$ interquartile range. 
Table 3 Multivariable ${ }^{a}$ HRs of estimated enterolignans, dietary fibre, and overall and breast cancer-specific mortality of postmenopausal breast cancer patients

\begin{tabular}{|c|c|c|c|c|c|c|c|c|c|c|}
\hline \multirow[b]{2}{*}{$\mathbf{Q}$} & \multirow[b]{2}{*}{$\begin{array}{l}\text { Median levels } \\
\left(\text { IQR) }\left(\mu \text { day }^{-1}\right)\right.\end{array}$} & \multirow[b]{2}{*}{$N$} & \multicolumn{4}{|c|}{ Overall mortality } & \multicolumn{4}{|c|}{ Breast cancer-specific mortality } \\
\hline & & & Deaths & HR & $(95 \% \mathrm{Cl})$ & $P_{\text {Trend }}$ & $\begin{array}{c}\text { Breast cancer } \\
\text { deaths }\end{array}$ & HR & $(95 \% \mathrm{Cl})$ & $P_{\text {Trend }}$ \\
\hline \multicolumn{11}{|c|}{ Enterolactone } \\
\hline 1 & $\mid 46.0(41.9)$ & 530 & 84 & 1.00 & Ref & & 59 & 1.00 & Ref & \\
\hline 2 & $211.9(28.6)$ & 531 & 74 & 0.87 & $(0.62-1.22)$ & & 54 & 0.88 & $(0.59-1.32)$ & \\
\hline 3 & $274.3(32.8)$ & 530 & 53 & 0.69 & $(0.48-1.00)$ & & 38 & 0.77 & $(0.50-1.20)$ & \\
\hline \multicolumn{11}{|c|}{ Enterodiol } \\
\hline I & | $86.9(59.8)$ & 530 & 76 & 1.00 & Ref & & 54 & 1.00 & Ref & \\
\hline 2 & $279.8(39.5)$ & 531 & 76 & 0.95 & $(0.67-1.33)$ & & 53 & 0.92 & $(0.61-1.39)$ & \\
\hline 3 & $366.8(50.2)$ & 530 & 70 & 0.97 & $(0.69-1.37)$ & & 53 & 1.07 & $(0.72-1.61)$ & \\
\hline 4 & $499.9(89.0)$ & 531 & 53 & 0.79 & $(0.54-1.15)$ & & 37 & 0.84 & $(0.53-1.33)$ & \\
\hline 5 & $857.5(368.6)$ & 531 & 46 & 0.63 & $(0.42-0.95)$ & 0.02 & 38 & 0.81 & $(0.51-1.29)$ & 0.40 \\
\hline \multicolumn{11}{|c|}{ Fibre } \\
\hline 4 & $23.2(1.9)^{b}$ & 530 & 53 & 0.64 & $(0.43-0.95)$ & & 41 & 0.71 & $(0.44-1.14)$ & \\
\hline 5 & $28.9(5.7)^{b}$ & 531 & 53 & 0.52 & $(0.32-0.82)$ & 0.01 & 41 & 0.64 & $(0.37-1.11)$ & 0.01 \\
\hline
\end{tabular}

Abbreviations: $\mathrm{Cl}=$ confidence interval; $\mathrm{ER}=$ oestrogen receptor; $\mathrm{HR}=$ hazard ratio; $\mathrm{IQR}=$ interquartile range; $\mathrm{PR}=$ progesterone receptor; $\mathrm{Q}=$ quantile. ${ }^{\mathrm{a}} \mathrm{Stratified}$ by age at diagnosis. Adjusted for tumour size, nodal status, metastasis, grade, ER/PR status, breast cancer detection type, diabetes, menopausal hormone therapy use at diagnosis, study centre, and energy intake. ${ }^{\mathrm{b}}$ In $\mathrm{g} \mathrm{day}^{-1}$.

Table 4 Multivariable ${ }^{a}$ HRs of enterolignans and overall mortality of postmenopausal breast cancer patients by dietary fibre intake

\begin{tabular}{|c|c|c|c|c|c|c|}
\hline \multirow[b]{2}{*}{$\mathbf{Q}$} & \multicolumn{3}{|c|}{ Low fibre intake ${ }^{b}$} & \multicolumn{3}{|c|}{ High fibre intake ${ }^{b}$} \\
\hline & HR & $(95 \% \mathrm{Cl})$ & $P_{\text {Trend }}$ & HR & $(95 \% \mathrm{Cl})$ & $P_{\text {Trend }}$ \\
\hline \multicolumn{7}{|c|}{ Enterolactone } \\
\hline I & 1.00 & Ref & & 1.00 & Ref & \\
\hline 2 & 0.82 & $(0.56-1.20)$ & & 2.07 & $(0.67-6.46)$ & \\
\hline 3 & 0.65 & $(0.40-1.07)$ & & 1.39 & $(0.48-4.03)$ & \\
\hline 4 & 0.84 & $(0.44-1.58)$ & & 2.04 & $(0.7 \mid-5.18)$ & \\
\hline 5 & 0.32 & $(0.10-1.04)$ & 0.03 & 1.25 & $(0.44-3.58)$ & 0.08 \\
\hline \multicolumn{7}{|c|}{ Enterodiol } \\
\hline I & 1.00 & Ref & & 1.00 & Ref & \\
\hline 2 & 0.91 & $(0.63-1.33)$ & & 1.48 & $(0.50-4.42)$ & \\
\hline 3 & 0.90 & $(0.57-1.42)$ & & 1.50 & $(0.54-4.16)$ & \\
\hline 4 & 0.39 & $(0.16-0.99)$ & & 1.58 & $(0.57-4.37)$ & \\
\hline 5 & 0.48 & $(0.21-1.07)$ & 0.01 & 1.08 & $(0.38-3.04)$ & 0.05 \\
\hline
\end{tabular}

Abbreviations: $\mathrm{Cl}=$ confidence interval; $\mathrm{ER}=$ oestrogen receptor; $\mathrm{HR}=$ hazard ratio; $\mathrm{PR}=$ progesterone receptor, $\mathrm{Q}=$ quantile. ${ }^{\mathrm{a}}$ Stratified by age at diagnosis. Adjusted for tumour size, nodal status, metastasis, grade, ER/PR status, breast cancer detection type, diabetes, menopausal hormone therapy use at diagnosis, study centre, and energy intake. ${ }^{b}$ Below vs equal to or above the median dietary fibre intake.

The estimation of enterolignan - the bioactive forms in the human body - using the method by Thompson et al (1991), which is based on in vitro fermentation of various plant foods with human faecal bacteria, has several strengths. It indirectly accounts for all enterolignan precursors and covers the long-term exposure to enterolignans. Nevertheless, the results must be interpreted cautiously as the estimation does not account for intra- and inter-individual variation of gut bacteria and metabolism. Also, the estimation is based on data collected in the early 1990s but, to our knowledge, there are no other data available to estimate the intestinally produced amounts of enterolactone and enterodiol, and this approach was also used by a previous study (Touillaud et al, 2007).
Dietary intake of bread, vegetables, and fruits, which are important sources of lignans, was not individually associated with breast cancer prognosis. Intake of seeds, which are rich sources of lignans (Penalvo et al, 2005), was associated with a nonsignificantly decreased overall mortality, but there was no significant dose-response relationship. Of note is that seeds contain other food constituents, like $\alpha$-linoleic acids (present in flaxseed), that have been shown to have anti-carcinogenic and anti-proliferative properties, which could render a protective effect (Wang et al, 2005; Bozan and Temelli, 2008).

So far, no other study has assessed the association between estimated enterolignans and breast cancer prognosis. Comparison of our findings with results on dietary lignan intake may not be appropriate. Nevertheless, in two smaller studies (each with $\sim 800$ postmenopausal women) conducted in the United States, higher dietary lignan intake was associated with lower mortality after breast cancer in one (McCann et al, 2009) but not in the other (Fink et al, 2007). Lignan intake was very different in these studies - one reporting a median intake of $245 \mu \mathrm{g} \mathrm{day}^{-1}$ (McCann et al, 2009) and the other reporting 10 times higher intake levels $\left(0\right.$ to $>9 \mathrm{mg} \mathrm{day}^{-1}$ ) (Fink et al, 2007). In line with our results, a recent Danish study observed a significantly increased survival with higher plasma enterolactone levels (Olsen et al, 2011).

Lignans have been found in high amounts in fibre-rich foods (e.g., cereals, wholegrains), and enterolactone concentrations were primarily explained by vegetable, rye, and fibre intake in Finnish men (Nurmi et al, 2010). In our study, the primary sources of estimated enterolignans were intake of bread (white, brown, and wholegrain), vegetables, and fruits, which are also rich sources of fibre. Fibre intake could affect breast cancer risk by several mechanisms, including stimulation of the intestinal microflora, reduction of the enterohepatic oestrogen circulation, and thereby reduction of oestrogen concentrations in the body (Adlercreutz, 2007; Sonestedt and Wirfält, 2010). Additionally, increased fibre intake was found to be related to lower serum oestradiol levels in women with breast cancer (Rock et al, 2004). 
Table 5 HRs of phyto-oestrogen-rich foods and overall and breast cancer-specific mortality of postmenopausal breast cancer patients

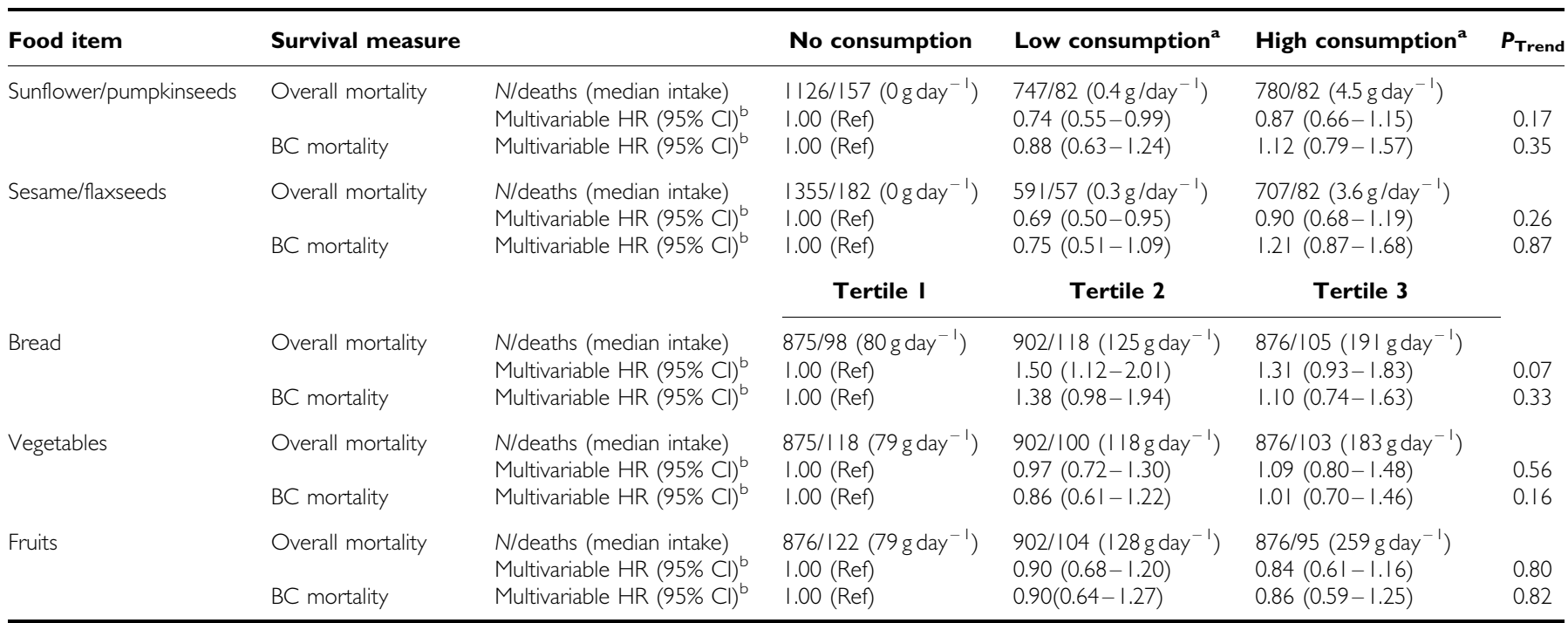

Abbreviations: $\mathrm{BC}=$ breast cancer-specific; $\mathrm{Cl}=$ confidence interval; $\mathrm{ER}=$ oestrogen receptor; $\mathrm{HR}=$ hazard ratio; PR= progesterone receptor. ${ }^{\mathrm{a}} \mathrm{Low}$ and high consumption defined by below and above/equal to median consumption of the consumers, respectively. ' $S$ Stratified by age at diagnosis. Adjusted for tumour size, nodal status, metastasis, grade, ER/PR status, breast cancer detection type, diabetes, menopausal hormone therapy use at diagnosis, study centre, and energy intake. 'Stratified by age at diagnosis.

To account for potential confounding by fibre, we adjusted the multivariable regression models for estimated enterolignans and OS by fibre intake. High levels of estimated enterolignans were no longer significantly associated with overall mortality, probably because of their high correlation with fibre, which may have introduced collinearity in the multivariable models. Also, the association between dietary fibre and overall survival was no longer significant after adjustment for enterolactone. Adjustment for fibre intake was not found to affect the association of lignan intake with postmenopausal breast cancer risk in a study conducted in France (Touillaud et al, 2007). However, the observation of a significant association of estimated enterolignans with a better prognosis in those with low dietary fibre intake strengthens the hypothesis that enterolignans may influence the prognosis of postmenopausal breast cancer independent of fibre intake. Furthermore, it has been suggested that high lignan intake might be an indicator of a healthy lifestyle (Sonestedt and Wirfält, 2010). However, adjustment for lifestyle factors including physical activity, BMI, alcohol, and smoking did not affect the associations observed for enterolignans.

No significant effect heterogeneity by ER status of the tumours and menopausal hormone therapy use at diagnosis was observed for the association of estimated enterolignans and fibre with overall mortality, which is in line with the results of another study on dietary lignans and prognosis (Fink et al, 2007). Therefore, hormone-dependent and -independent mechanisms of action might be involved in the observed association with enterolignans. Enterolignans are able to bind to ERs, thereby preventing endogenous oestrogens from binding and inhibiting tumour growth stimulation (Adlercreutz and Mazur, 1997). In animal studies, several hormone-independent mechanisms have been suggested, such as inhibition of angiogenesis, tumour growth, and metastasis, as well as stimulation of apoptosis (Power et al, 2006; Saarinen et al, 2008, 2010). Moreover, an intervention with flaxseed in postmenopausal breast cancer patients resulted in an increased apoptosis and a decrease of tumour biological markers in tumour tissues (Thompson et al, 2005).

The strength of our study was the large population-based patient sample with complete follow-up and verification of causes of death using death certificates as well as the consideration of all relevant prognostic factors. Sensitivity analyses were performed, which showed that results were not affected by time of diagnosis and FFQ completion. Additionally, fibre intake, enterolignan levels, and lignan-rich foods (except for the seeds) were estimated using a validated dietary questionnaire. Thereby, a broad spectrum of dietary lignan sources was addressed. The FFQ assessed dietary habits over the entire 12 months before diagnosis and, thus, captures the long-term situation of enterolignan exposure.

In the interpretation of our results, we also need to address some limitations. The assessment of dietary intake may be subject to measurement errors that are not only due to recall bias but also to the estimation using food-composition databases, which may not be complete for the whole range of foods consumed. Dietary changes after diagnosis, which could have contributed to survival, were not accounted for in this analysis. Although we collected comprehensive data and assessed many possible confounding factors, residual confounding could not be entirely ruled out. Also, sample size was limited in subgroups and therefore results must be interpreted cautiously.

In conclusion, we found some evidence for a better prognosis in postmenopausal breast cancer patients who have high estimated enterolignan and dietary fibre exposures. The associations of estimated enterolignans with survival were independent of ER status of the tumour and may, in part, be independent of dietary fibre intake. However, further investigations on enterolignans measured in serum or urine and breast cancer prognosis are warranted to confirm our results and to disentangle the possible mechanisms involved.

\section{ACKNOWLEDGEMENTS}

The 'Deutsche Krebshilfe e.V.' is funding the MARIEplus study (grant numbers: 108253, 108419). KB and AKZ are funded by the 'Deutsche Forschungsgemeinschaft, Graduiertenkolleg 793: Epidemiology of communicable and chronic non-communicable diseases and their interrelationships'. We thank U Eilber, C Krieg, D Zoller, R Birr, and S Behrens for technical support.

Supplementary Information accompanies the paper on British Journal of Cancer website (http://www.nature.com/bjc) 


\section{REFERENCES}

Adlercreutz H (2007) Lignans and human health. Crit Rev Clin Lab Sci 44: $483-525$

Adlercreutz H, Hockerstedt K, Bannwart C, Bloigu S, Hamalainen E, Fotsis T, Ollus A (1987) Effect of dietary components, including lignans and phytoestrogens, on enterohepatic circulation and liver metabolism of estrogens and on sex hormone binding globulin (SHBG). J Steroid Biochem 27: $1135-1144$

Adlercreutz H, Mazur W (1997) Phyto-oestrogens and Western diseases. Ann Med 29: 95-120

Bohlscheid-Thomas S, Hoting I, Boeing H, Wahrendorf J (1997a) Reproducibility and relative validity of energy and macronutrient intake of a food frequency questionnaire developed for the German part of the EPIC project. European Prospective Investigation into Cancer and Nutrition. Int J Epidemiol 26(Suppl 1): S71 - S81

Bohlscheid-Thomas S, Hoting I, Boeing H, Wahrendorf J (1997b) Reproducibility and relative validity of food group intake in a food frequency questionnaire developed for the German part of the EPIC project. European Prospective Investigation into Cancer and Nutrition. Int J Epidemiol 26(Suppl 1): S59-S70

Bozan B, Temelli F (2008) Chemical composition and oxidative stability of flax, safflower and poppy seed and seed oils. Bioresour Technol 99: $6354-6359$

Buck K, Zaineddin AK, Vrieling A, Linseisen J, Chang-Claude J (2010) Meta-analyses of lignans and enterolignans in relation to breast cancer risk. Am J Clin Nutr 92: 141-153

Fink BN, Steck SE, Wolff MS, Britton JA, Kabat GC, Gaudet MM, Abrahamson PE, Bell P, Schroeder JC, Teitelbaum SL, Neugut AI, Gammon MD (2007) Dietary flavonoid intake and breast cancer survival among women on Long Island. Cancer Epidemiol Biomarkers Prev 16: $2285-2292$

Flesch-Janys D, Slanger T, Mutschelknauss E, Kropp S, Obi N, Vettorazzi E, Braendle W, Bastert G, Hentschel S, Berger J, Chang-Claude J (2008) Risk of different histological types of postmenopausal breast cancer by type and regimen of menopausal hormone therapy. Int J Cancer 123: $933-941$

Grambsch PM, Therneau TM (1994) Proportional hazards tests and diagnostics based on weighted residuals. Biometrika 81: 515-526

Holmes MD, Stampfer MJ, Colditz GA, Rosner B, Hunter DJ, Willett WC (1999) Dietary factors and the survival of women with breast carcinoma. Cancer 86: $826-835$

Kellen E, Vansant G, Christiaens MR, Neven P, Van LE (2009) Lifestyle changes and breast cancer prognosis: a review. Breast Cancer Res Treat 114: $13-22$

Kroenke CH, Fung TT, Hu FB, Holmes MD (2005) Dietary patterns and survival after breast cancer diagnosis. J Clin Oncol 23: 9295 - 9303

Linseisen J, Piller R, Hermann S, Chang-Claude J (2004) Dietary phytoestrogen intake and premenopausal breast cancer risk in a German case-control study. Int J Cancer 110: 284-290

McCann SE, Thompson LU, Nie J, Dorn J, Trevisan M, Shields PG, Ambrosone CB, Edge SB, Li HF, Kasprzak C, Freudenheim JL (2009) Dietary lignan intakes in relation to survival among women with breast cancer: the Western New York Exposures and Breast Cancer (WEB) Study. Breast Cancer Res Treat 122: 229-235

Mense SM, Hei TK, Ganju RK, Bhat HK (2008) Phytoestrogens and breast cancer prevention: possible mechanisms of action. Environ Health Perspect 116: $426-433$

Mueller SO, Simon S, Chae K, Metzler M, Korach KS (2004) Phytoestrogens and their human metabolites show distinct agonistic and antagonistic properties on estrogen receptor alpha (ERalpha) and ERbeta in human cells. Toxicol Sci 80: $14-25$

Nurmi T, Mursu J, Penalvo JL, Poulsen HE, Voutilainen S (2010) Dietary intake and urinary excretion of lignans in Finnish men. Br J Nutr 103: $677-685$

Olsen A, Christensen J, Knudsen KE, Johnsen NF, Overvad K, Tjonneland A (2011) Prediagnostic plasma enterolactone levels and mortality among women with breast cancer. Breast Cancer Res Treat 128(3): 883-889

Penalvo JL, Haajanen KM, Botting N, Adlercreutz H (2005) Quantification of lignans in food using isotope dilution gas chromatography/mass spectrometry. J Agric Food Chem 53: 9342 - 9347

Penttinen P, Jaehrling J, Damdimopoulos AE, Inzunza J, Lemmen JG, van der SP, Pettersson K, Gauglitz G, Makela S, Pongratz I (2007) Diet-derived polyphenol metabolite enterolactone is a tissue-specific estrogen receptor activator. Endocrinology 148: $4875-4886$

Power KA, Saarinen NM, Chen JM, Thompson LU (2006) Mammalian lignans enterolactone and enterodiol, alone and in combination with the isoflavone genistein, do not promote the growth of MCF-7 xenografts in ovariectomized athymic nude mice. Int J Cancer 118: 1316-1320

Rock CL, Flatt SW, Thomson CA, Stefanick ML, Newman VA, Jones LA, Natarajan L, Ritenbaugh C, Hollenbach KA, Pierce JP, Chang RJ (2004) Effects of a high-fiber, low-fat diet intervention on serum concentrations of reproductive steroid hormones in women with a history of breast cancer. J Clin Oncol 22: 2379-2387

Royston P, Ambler G, Sauerbrei W (1999) The use of fractional polynomials to model continuous risk variables in epidemiology. Int J Epidemiol 28: $964-974$

Saarinen NM, Abrahamsson A, Dabrosin C (2010) Estrogen-induced angiogenic factors derived from stromal and cancer cells are differently regulated by enterolactone and genistein in human breast cancer in vivo. Int $J$ Cancer 127: $737-745$

Saarinen NM, Warri A, Dings RP, Airio M, Smeds AI, Makela S (2008) Dietary lariciresinol attenuates mammary tumor growth and reduces blood vessel density in human MCF-7 breast cancer xenografts and carcinogen-induced mammary tumors in rats. Int $J$ Cancer 123: $1196-1204$

Schemper M, Smith TL (1996) A note on quantifying follow-up in studies of failure time. Control Clin Trials 17: 343-346

Sonestedt E, Wirfält E (2010) Enterolactone and breast cancer: methodological issues may contribute to conflicting results in observational studies. Nutr Res 30: 667-677

Thompson LU, Chen JM, Li T, Strasser-Weippl K, Goss PE (2005) Dietary flaxseed alters tumor biological markers in postmenopausal breast cancer. Clin Cancer Res 11: 3828-3835

Thompson LU, Robb P, Serraino M, Cheung F (1991) Mammalian lignan production from various foods. Nutr Cancer 16: 43-52

Touillaud MS, Thiebaut AC, Fournier A, Niravong M, Boutron-Ruault MC, Clavel-Chapelon F (2007) Dietary lignan intake and postmenopausal breast cancer risk by estrogen and progesterone receptor status. J Natl Cancer Inst 99: 475-486

Velentzis LS, Cantwell MM, Cardwell C, Keshtgar MR, Leathem AJ, Woodside JV (2009) Lignans and breast cancer risk in pre- and post-menopausal women: meta-analyses of observational studies. Br J Cancer 100: 1492-1498

Wang L, Chen J, Thompson LU (2005) The inhibitory effect of flaxseed on the growth and metastasis of estrogen receptor negative human breast cancer xenografts is attributed to both its lignan and oil components. Int J Cancer 116: $793-798$

This work is published under the standard license to publish agreement. After 12 months the work will become freely available and the license terms will switch to a Creative Commons Attribution-NonCommercial-Share Alike 3.0 Unported License. 